\title{
Hypoxia in Obesity and Diabetes: Potential Therapeutic Effects of Hyperoxia and Nitrate
}

\author{
Reza Norouzirad, ${ }^{1,2}$ Pedro González-Muniesa, ${ }^{3,4,5,6}$ and Asghar Ghasemi ${ }^{1}$ \\ ${ }^{1}$ Endocrine Physiology Research Center, Research Institute for Endocrine Sciences, Shahid Beheshti University of Medical Sciences, \\ Tehran, Iran \\ ${ }^{2}$ Dezful University of Medical Sciences, Dezful, Iran \\ ${ }^{3}$ Centre for Nutrition Research, School of Pharmacy and Nutrition, University of Navarra, Pamplona, Spain \\ ${ }^{4}$ Department of Nutrition, Food Sciences and Physiology, School of Pharmacy and Nutrition, University of Navarra, Pamplona, Spain \\ ${ }^{5}$ IDISNA Navarra's Health Research Institute, Pamplona, Spain \\ ${ }^{6}$ CIBER Fisiopatología de la Obesidad y Nutrición (CIBERobn), Instituto de Salud Carlos III, Madrid, Spain
}

Correspondence should be addressed to Asghar Ghasemi; ghasemi@endocrine.ac.ir

Received 4 December 2016; Revised 4 April 2017; Accepted 11 April 2017; Published 21 May 2017

Academic Editor: Victor M. Victor

Copyright (c) 2017 Reza Norouzirad et al. This is an open access article distributed under the Creative Commons Attribution License, which permits unrestricted use, distribution, and reproduction in any medium, provided the original work is properly cited.

\begin{abstract}
The prevalence of obesity and diabetes is increasing worldwide. Obesity and diabetes are associated with oxidative stress, inflammation, endothelial dysfunction, insulin resistance, and glucose intolerance. Obesity, a chronic hypoxic state that is associated with decreased nitric oxide (NO) bioavailability, is one of the main causes of type 2 diabetes. The hypoxia-inducible factor- $1 \alpha(\mathrm{HIF}-1 \alpha)$ is involved in the regulation of several genes of the metabolic pathways including proinflammatory adipokines, endothelial NO synthase (eNOS), and insulin signaling components. It seems that adipose tissue hypoxia and NOdependent vascular and cellular dysfunctions are responsible for other consequences linked to obesity-related disorders. Although hyperoxia could reverse hypoxic-related disorders, it increases the production of reactive oxygen species (ROS) and decreases the production of NO. Nitrate can restore NO depletion and has antioxidant properties, and recent data support the beneficial effects of nitrate therapy in obesity and diabetes. Although it seems reasonable to combine hyperoxia and nitrate treatments for managing obesity/diabetes, the combined effects have not been investigated yet. This review discusses some aspects of tissue oxygenation and the potential effects of hyperoxia and nitrate interventions on obesity/diabetes management. It can be proposed that concomitant use of hyperoxia and nitrate is justified for managing obesity and diabetes.
\end{abstract}

\section{Introduction}

Obesity and diabetes, two major health problems worldwide, have shown an increasing trend in their prevalence over time [1]. Obesity, one of the main causes of type 2 diabetes [2], is associated with an increased number and size of triglyceridefilled white adipocytes [3]. Obesity is a state of hypoxia and low blood flow [4]. In this sense, hyperoxia exposure has been evaluated as a treatment for obesity and its related disorders $[5,6]$. Although hyperoxia has shown beneficial effects for obesity management, it may result in nitric oxide (NO) depletion and induction of oxidative stress [7-9]. Interestingly, nitrate, a new proposed therapeutic agent for type 2 diabetes [10], restores NO depletion and has antioxidant properties [11]. This study reviews the effects of hyperoxia and nitrate interventions on the management of obesity and type 2 diabetes.

\section{Adipose Tissue}

There are three types of adipocytes or adipose tissues [12]. White adipose tissue (WAT) stores energy and lipids, in the form of triglycerides $[3,12]$. Brown adipose tissue (BAT) dissipates energy and acts as a heat producer; BAT cells produce uncoupling protein 1 (UCP1), which uncouples the respiratory chain, that is, proton transport without phosphorylation, 
TABLE 1: Some characteristics of the three types of adipocytes.

\begin{tabular}{|c|c|c|c|c|}
\hline & White adipocytes & Brown adipocytes & Brite or beige adipocytes & References \\
\hline Origin in adulthood & $\begin{array}{c}\text { Mesenchymal } \\
\text { and endothelial precursors }\end{array}$ & $\begin{array}{l}\text { Mesenchymal precursors, } \\
\text { muscle satellite cell, and } \\
\text { endothelial precursors }\end{array}$ & $\begin{array}{l}\text { WAT adipocyte and } \\
\text { endothelial precursors }\end{array}$ & {$[12,14]$} \\
\hline Transcription factor & $\mathrm{Myf5}^{-}$and Tcf21 & $\mathrm{Myf}^{+}$ & $\operatorname{Tcf} 21$ & {$[14]$} \\
\hline Specific gene expression & Leptin & $\mathrm{UCP} 1$ and $\mathrm{Zic} 1$ & UCP1 and Hoxc9 & {$[12,20,21]$} \\
\hline $\begin{array}{l}\text { Number of } \\
\text { mitochondria }\end{array}$ & Low & High & High & {$[12,13]$} \\
\hline Main function & Lipid storage & Heat producer & Heat producer & {$[12,13]$} \\
\hline Effect on obesity & Obesogenic & Antiobesity & Antiobesity & {$[13]$} \\
\hline Histological phenotype & $\begin{array}{l}\text { Large cells with one huge } \\
\text { lipid vacuole }\end{array}$ & $\begin{array}{l}\text { Small cells with several lipid } \\
\text { vacuoles }\end{array}$ & $\begin{array}{l}\text { Small cells with several } \\
\text { lipid vacuoles }\end{array}$ & {$[14,20]$} \\
\hline $\begin{array}{l}\text { Anatomical description } \\
\text { of fat depots (mice) }\end{array}$ & $\begin{array}{l}\text { Epididymal, mesenteric, } \\
\text { inguinal, retroperitoneal, } \\
\text { and cardiac }\end{array}$ & $\begin{array}{c}\text { Interscapular, axillary, cervical, } \\
\text { and mediastinic }\end{array}$ & $\begin{array}{l}\text { Inguinal, cardiac, and } \\
\text { retroperitoneal }\end{array}$ & {$[21]$} \\
\hline
\end{tabular}

Hoxc9: homeobox9; Myf5: myogenic factor 5; Tcf21: transcription factor 21; UCP 1: uncoupling protein 1; WAT: white adipose tissue; Zic1: zinc finger protein in cerebellum 1.

inducing thermogenesis instead of ATP production [13]. The third type is the brite or beige adipocytes [12]. Beige cells share some characteristics with BAT cells and others with WAT cells [14]. cAMP-induced UCP1 expression is higher in beige than in BAT cells; in addition, long-term treatment with thiazolidinedione (TZD) can induce higher UCP1 expression in beige cells than in WAT cells (8- to 10-fold versus 4- to 5-fold) [15].

Anatomically, adipose tissues are distributed in central adipose tissues (visceral and upper abdominal subcutaneous fats) and peripheral adipose tissues (hip and gluteofemoral fats) [16]. Visceral fat accumulation is associated with oxidative stress and inflammation $[17,18]$. Adipose tissue is heterogeneous and includes adipocytes, vascular cells, and immune cells [16]. This tissue is metabolically active; for example, WAT is an endocrine organ and secretes a large variety of adipokines [19]. Table 1 shows some characteristics of different adipocytes.

\section{Inflammation of Obese Adipose Tissue and Insulin Resistance}

\subsection{Obese Adipose Tissue}

3.1.1. Adipocyte Death and Turnover. In humans, the turnover of adipocytes is low, that is, $\sim 10 \%$ per year, a rate that does not change in the early stages of obesity [22]. During the generation of WAT adipocytes, the expression of antiapoptotic factors such as B-cell lymphoma $2\left(\mathrm{Bcl}_{2}\right)$ and fliceinhibitory protein (FLIP) leads to prolonged cell life [23]; insulin-like growth factor I (IGF-I) can decrease apoptosis of human fat cells by sustaining the antiapoptotic factors [24]. $\mathrm{Bcl}_{2}$ expression is negatively correlated with body mass index and inflammatory cytokines (interleukin-6 (IL-6) and tumor necrosis factor alpha $(\mathrm{TNF}-\alpha)$ ) [25]. Strissel et al. have reported that adipocyte death in epididymal adipose tissue of C57BL/6 male mice on a high-fat diet is increased from $0.1 \%$ at week 1 to $16 \%$ at week 12 [26]. In addition, the expression of proapoptotic caspases (CASP3, CASP7, CASP8, and CASP9) is increased, while the expression of $\mathrm{Bcl}_{2}$ (an antiapoptotic factor) is decreased in obesity [25]. Inflammatory factors such as TNF- $\alpha$, IL-6, IL- $1 \beta$, monocyte chemoattractant protein-1 (MCP1), and macrophage recruitment are also increased in obesity; these factors negatively affect adipocyte metabolism and its lipid storage capacity [2, 25, 27]. Rammos et al. have shown that 4 weeks of dietary nitrate (sodium nitrate $150 \mu \mathrm{mol} / \mathrm{kg}$ body weight) administration can reduce macrophage migration inflammatory factor (MIF), which is a proinflammatory and atherogenic factor [28]. In obesity, BAT cell apoptosis is increased due to the decrease in $\mathrm{Bcl}_{2}$ [29] and increase in TNF- $\alpha$ [30]; however, low temperature can upregulate the $\mathrm{Bcl}_{2}$ gene expression and may protect BAT against apoptosis in cold situations [29].

3.1.2. Lipolysis and Inflammation in Adipocytes. The functions of adipose tissues vary greatly between obese and lean subjects [25, 31]. For example, basal lipolysis is higher in obese adipose tissues than in lean ones [31]. In addition, elevated levels of fatty acids due to the increased lipolysis, highfat diets, and hypoxia can result in ectopic fat deposition (as triglycerides and long-chain fatty acid forms) in skeletal muscles, liver, and $\beta$-cells; this increased ectopic fat deposition interferes with the normal functions of these tissues; for instance, the high levels of blood fatty acids and TNF- $\alpha$ occurring in obesity can induce insulin resistance [32-34]. Furthermore, long-term effects of medium- and long-chain fatty acids on $\beta$-cells are $\mathrm{K}^{+}$channels opening and decrease in insulin secretion [35]. By contrast, fatty acids released due to lipolysis in lean subjects bind to coenzyme A to form acyl-CoA, which enters the $\beta$-oxidation pathway instead of the circulation, hence reducing the pernicious effects of an excessive free fatty acid release to the blood [2]. In inflammatory states, TNF- $\alpha$, which is induced due to the increase in the numbers of both adipocytes and macrophages, inhibits normal differentiation of preadipocytes and induces proinflammatory phenotypes [36]. TNF- $\alpha$ inhibits peroxisome proliferator-activated receptor- $\gamma(\operatorname{PPAR} \gamma)$, which is involved in liver diseases and also lipid metabolism [37, 38]. Inhibition of PPAR $\gamma$ increases circulating free fatty acids and therefore 
TABLE 2: Some adipose tissue secreted adipokines or cytokines.

\begin{tabular}{|c|c|c|}
\hline $\begin{array}{l}\text { Adipo/ } \\
\text { cytokines }\end{array}$ & Function & Reference \\
\hline Adiponectin & $\begin{array}{l}\text { Increases } \beta \text {-oxidation, insulin sensitivity via AMPK; increases glucose uptake and glucose tolerance. } \\
\text { Decreased adiponectin is related to obesity, TNF- } \alpha \text { upregulation, and eNOS downregulation. }\end{array}$ & {$[41,42]$} \\
\hline Sfrp5 & Is increased by calorie restriction diet and has an anti-inflammatory action. & [43] \\
\hline Adipolin & $\begin{array}{c}\text { Is known as adipose-derived insulin-sensitizing factor, improves glucose metabolism, and decreases insulin } \\
\text { resistance and inflammation. }\end{array}$ & {$[44]$} \\
\hline Apelin & $\begin{array}{l}\text { Inhibits diet-induced obesity, due to its improvement of vascular integrity. It is positively correlated with BMI, } \\
\text { and it is upregulated by insulin in obesity. }\end{array}$ & [45-47] \\
\hline $\operatorname{PPAR} \gamma$ & $\begin{array}{c}\text { Induces storage of lipids and adipogenesis and reduces lipotoxicity; it also regulates whole body insulin } \\
\text { sensitivity. }\end{array}$ & {$[48]$} \\
\hline Leptin & $\begin{array}{l}\text { Is a cytokine-like hormone, which inhibits food intake and energy expenditure. It impairs NO-mediated } \\
\text { component. }\end{array}$ & [49] \\
\hline Resistin & Is increased in genetic- and diet-induced obesity models. It is specific for WAT and causes insulin resistance. & {$[50]$} \\
\hline
\end{tabular}

AMPK: adenosine monophosphate-activated protein kinase; BMI: body mass index; eNOS: endothelial nitric oxide (NO) synthase; Sfrp5: soluble (secreted) frizzled-related protein 5; WAT: white adipose tissue.

intensifies ectopic fat deposition in the liver, skeletal muscles, and other metabolic organs $[2,37,38]$. These conditions along with insulin resistance, low insulin production, and/ or hyperphagia can worsen the situation and lead to hyperglycemia, glucose intolerance, and eventually diabetes.

\subsubsection{Adipose Tissue Macrophages and Inflammation. It has} been estimated that the amount of adipose tissue macrophage infiltration in lean mice and humans is under $10 \%$ [39]. However, this amount is increased up to $50 \%$ in extremely obese mice and up to $40 \%$ in obese humans [39]. Recently, two types of macrophages have been described, based on their activation: M1, classically activated and M2, alternatively activated. A shift from M2 to M1 has been reported in obesity and inflammation [40]. Increased TNF$\alpha$ upregulates MCP1 expression and leads to adipose tissue macrophage infiltration in obesity [16]. In addition to MCP1, other chemoattractants are also involved in macrophage recruitment to adipose tissues [16]. Some secreted hormones or molecules of adipose tissues are listed in Table 2.

3.2. Insulin Resistance in Obesity. The insulin signaling pathways have been previously reported in detail by several authors [51, 52]. As partly shown in Figure 1, phosphorylation of insulin receptor (IR) tyrosine, protein kinase B $(\mathrm{PKB})$, and Akt substrate of $160 \mathrm{kDa}(\mathrm{AS} 160)$ in insulin signaling pathways is impaired by hypoxia, changes that are reversible by reoxygenation [53]; hypoxia also inhibits the insulin-induced phosphorylation of IR substrate 1 (IRS-1) and IRS-2 [53]. It has however been shown that the deletion of hepatic prolyl hydroxylase domain enzyme 3 (PHD3) stabilizes the hypoxia-inducible factor- $2 \alpha$ (HIF- $2 \alpha$ ), a key factor of hypoxia responses, and improves insulin sensitivity [54] (see Stabilization and Destabilization of HIF-1 $\alpha$ ). As shown in Figure 1, hypoxia results in increased inflammatory factors and free fatty acids that lead to insulin resistance via the activation of c-Jun amino-terminal kinase 1 (JNK-1) [55]. The activation of JNK-1 interferes with insulin signaling via phosphorylation of IRS-1 on serine 307 (Ser307) residue [56, 57]. IRS- 1 is activated by insulin via tyrosine phosphorylation of
IRS-1 in the normal signaling pathway, but the Ser307 phosphorylation of IRS decreases its ability to phosphorylate tyrosine and can therefore cause insulin resistance [57-59]. Hirosumi et al. have reported that Ser307 phosphorylation of IRS-1 is increased in wild type obese mice, but not in Jnk $1^{-/-}$mice [57].

Circulating levels of inflammatory factors including free fatty acids and TNF- $\alpha$ are higher in obesity $[55,57,60]$; these factors activate JNK-1, resulting in insulin resistance, as aforementioned [59]. It should be noted that TNF- $\alpha$ does not directly inhibit IRS-1. The inactivation of JNK-1 in transgenic mice on a high-fat diet leads to increased fatty acid oxidation and energy consumption as well as decreased inflammation [61]. In addition, while basal reactive oxygen species (ROS) level has positive effects on both insulin secretion in $\beta$-cells and insulin signaling, ROS overproduction is detrimental and can lead to insulin resistance [62-64].

\subsection{Cellular Stress in Obesity}

3.3.1. Mitochondrial Stress. In obesity, the overproduction of ROS leads to adipocyte dysfunction. Increased substrates of the electron transport chain and an increased potential of the mitochondrial inner membrane are the main reasons for increased ROS, in particular the superoxide anion [65]. In addition, high glucose level in some cases of obesity can lead to increased ROS signaling [66]. The superoxide anion is converted to $\mathrm{H}_{2} \mathrm{O}_{2}$ by the enzyme superoxide dismutase; although it is more reactive than $\mathrm{H}_{2} \mathrm{O}_{2}$, the latter can pass across the cell membrane, thereby elevating the ROS levels in cytoplasm and affecting macromolecules $[65,67,68]$. In BAT and brite cells, ROS increases UCP1, which can lower the potential of mitochondrial membrane and can regulate ROS production $[65,69]$.

3.3.2. Endoplasmic Reticulum Stress. The enlargement of adipocytes leads to increase in protein synthesis, causing endoplasmic reticulum (ER) stress due to inappropriate folding. In addition, chronic high free fatty acid levels can also cause ER stress [70]; ER is a site for the synthesis of proteins, 


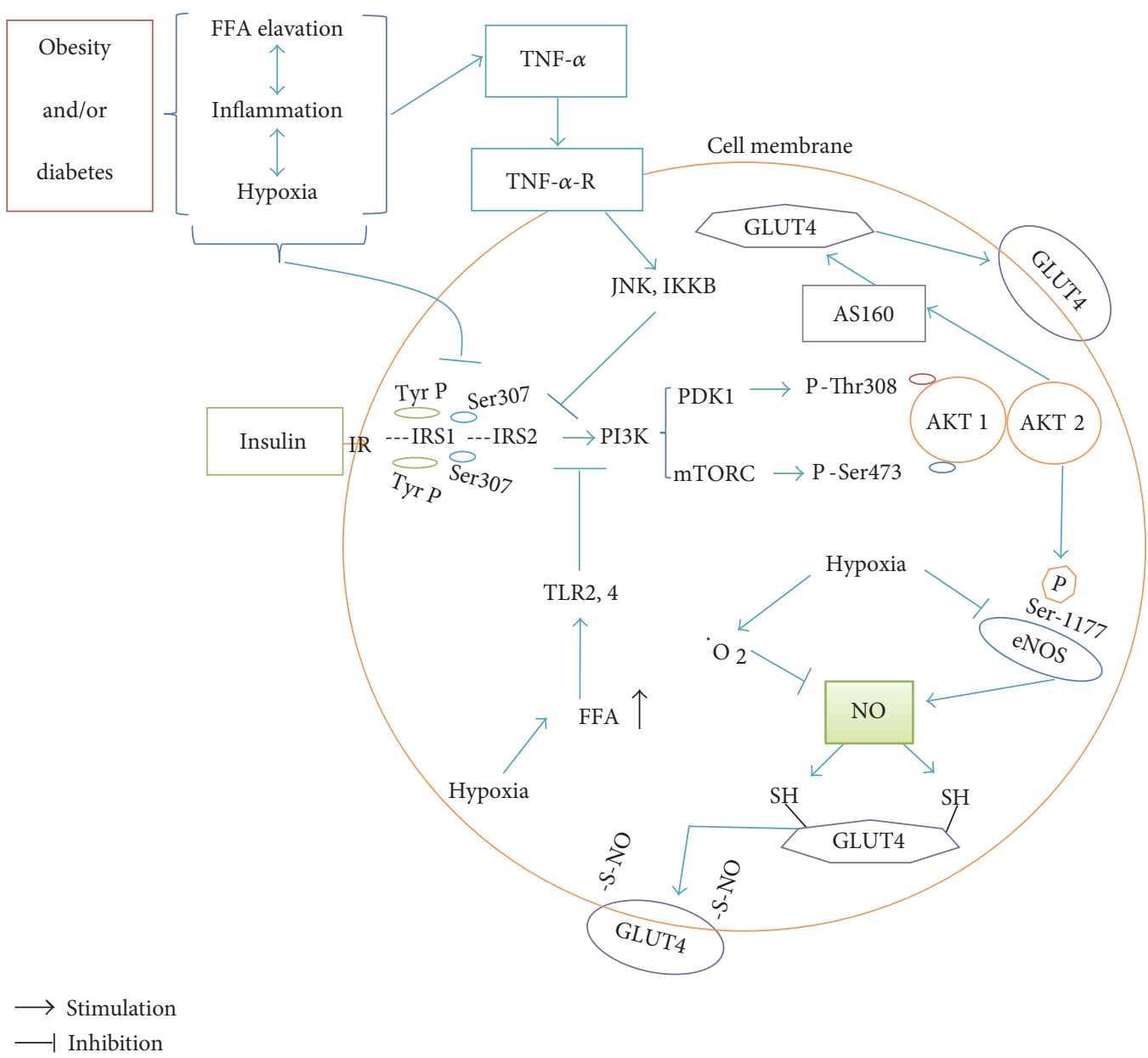

FIGURE 1: Insulin resistance in obesity. Obesity is associated with hypoxia, inflammation, and lipolysis. These conditions can lead to insulin resistance by impairment of insulin receptor substrate (IRS)/phosphatidyl inositol-3 kinase (PI3K)/AKT pathway. The c-Jun amino-terminal kinase (JNK), Toll-like receptors (TLRs), Akt substrate of $160 \mathrm{kDa}$ (AS160), and AKT/serine (Ser)-1177 are the sensing points that hypoxia and inflammatory factors can inhibit insulin signaling. It should be noted that not all the above signaling occurs in every cell. GLUT: glucose transporter; IKKB: I $\kappa$ B kinase $\beta$; IR: insulin receptor; mTORC: mammalian target of rapamycin complex; PDK1: 3-phosphoinositidedependent protein kinase 1; Ser307: serine 307; TNF- $\alpha$-R: tumor necrosis factor- $\alpha$ receptor; Tyr P: phosphorylated tyrosine.

sterols, and lipids; if any of these functions are disrupted, it results in ER stress and can cause apoptosis and $\beta$-cell death $[70,71]$, which may negatively affect the insulin production.

\section{Obese Adipose Tissue Oxygenation}

4.1. Hypoxic or Hyperoxic Status of the Adipocytes in Obesity. Oxygenation of adipocytes is different depending on their location and types [19]. Ye et al. have reported oxygen pressure $\left(\mathrm{PO}_{2}\right)$ of epididymal fat in lean and obese mice to be 47.9 and $15.2 \mathrm{~mm} \mathrm{Hg}$, respectively, a difference indicating $~ 70 \%$ reduction in the latter [72]. Furthermore, it has been reported that hypoxia-induced vascular endothelial growth factor (VEGF) expression is impaired in hyperglycemia/diabetes [73]. A 44\% decrease in capillary density and 58\% in VEGF mRNA in obese compared to lean individuals indicate that low $\mathrm{PO}_{2}$ levels in overweight and obesity do not result in neovascularization [74]. In obesity, free fatty acids are increased [75], which can induce the uncoupling of oxidation from phosphorylation in mitochondrial respiration via induction of uncoupling proteins such as adenine nucleotide translocase 2 (ANT2); ANT2 subsequently increases oxygen consumption, leading to cell hypoxia [76]. There is one report that despite the low blood flow of adipose tissues in obesity, it was suggested that there is an increase in oxygen tension due to low oxygen consumption in mitochondria [77]. Different assay methods $\left(\mathrm{O}_{2}\right.$ electrode versus optochemical measurement) could possibly explain these controversial results. To sum up, several studies have emphasized the hypoxic state of adipose tissues in obesity [4].

4.2. Cellular Responses to Hypoxia. Hypoxia can increase cell necrosis and apoptosis in humans and mice. Yin et al. have reported that in vitro hypoxia (1\% oxygen for 16 hours) causes $75 \%$ cell death in 3T3-L1 adipocytes via increased necrosis (40\%) and apoptosis (35\%) [34]. In obese mice and humans, adipocyte death is correlated with an increase in adipocyte size and macrophage recruitment [78]. Hypoxia has a key role in initiating obesity disorders through affecting multiple gene expressions (over 1000 genes) in adipocytes 


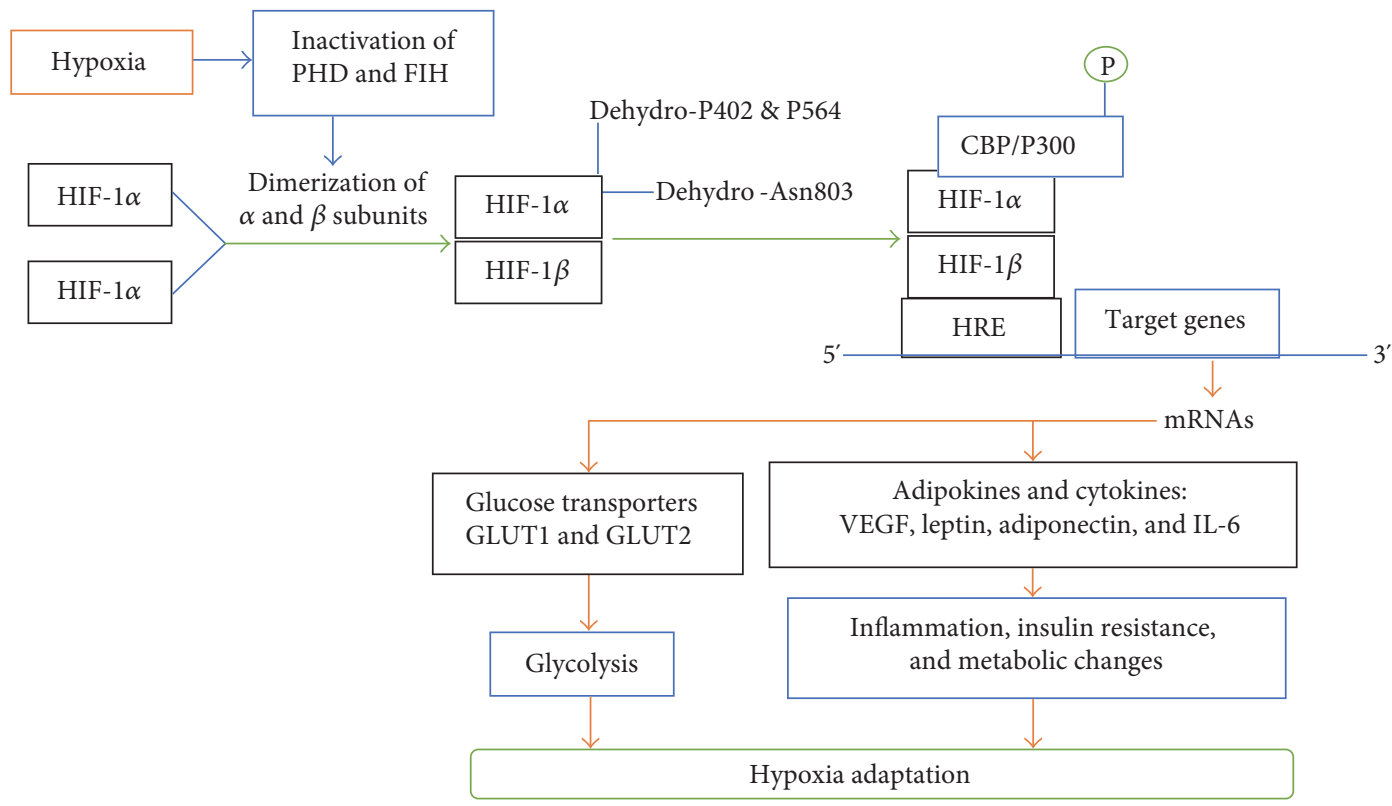

FIgURE 2: Hypoxia-inducible factor- $1 \alpha$ (HIF- $1 \alpha$ ) responses to hypoxia. HIF- $1 \alpha$ acts through up-/downregulation of $\sim 1300$ genes including glucose transporters (GLUTs), adipokines, and cytokines. CBP/p300: cAMP response element-binding protein- (CREB-) binding protein (CBP) and p300; Dehydro-Asn803: dehydroxylated asparagine 803; Dehydro-P402 and P564: dehydroxylated proline 402 and proline 564; FIH: factor-inhibiting hypoxia-inducible factor; HRE: hypoxia-response element; PHD: prolyl hydroxylase domain enzymes; VEGF: vascular endothelial growth factor.

[79], in particular HIF-1 $\alpha$ [76]. Inhibition of ANT2 and/or HIF- $1 \alpha$ can reverse the complications of obesity, for example, insulin resistance [76]. Furthermore, insulin can induce HIF$1 \alpha$ in 3T3-L1 adipocytes by a ROS-dependent mechanism [80]. In addition, ROS (in particular $\mathrm{H}_{2} \mathrm{O}_{2}$ ) can inhibit PHDs, via oxidation of $\mathrm{Fe}^{2+}$ to $\mathrm{Fe}^{3+}$, sustaining thereby the activation of HIF- $1 \alpha[81,82]$.

4.2.1. Inflammatory Responses to Hypoxia. Hypoxia affects cellular pathways by stimulation of lipolysis, inhibition of adipogenesis, and adipocyte differentiation $[19,83]$ and consequently increases free fatty acid levels [19]; this issue may be due to the downregulation of PPAR $\gamma$ gene expression in a hypoxic state [83-85]. Furthermore, hypoxia is correlated with an increased expression of macrophage inflammatory protein-1 $\alpha$ (MIP-1 $\alpha)$ and macrophage infiltration [74]. In obese mice, hypoxia increases expression of inflammatory genes in M1 macrophages, particularly in the adipose tissues [86]. Hypoxia induces HIF- $1 \alpha$-dependent and HIF- $1 \alpha$-independent inflammation in visceral but not in subcutaneous fat; this may be due to the presence of M1 macrophages in the former fat and M2 macrophages in the latter fat [86].

\subsubsection{HIF-1 $\alpha$, a Key Factor for Hypoxia Adaptation in Adipose Tissue}

(1) HIF-1 $\alpha$ Structure. HIFs are heterodimers of $\alpha$ and $\beta$ subunits [87]. The $\alpha$ subunit contains three isoforms, $\operatorname{HIF}-1 \alpha$, HIF- $2 \alpha$, and HIF- $3 \alpha$; HIF- $1 \alpha$ and HIF- $2 \alpha$ subunits are oxygen sensitive [88]. HIF- $1 \alpha$ is synthesized in environments with sufficient oxygen levels; however it is targeted for proteasome degradation. The HIF- $1 \beta$ subunit is a shared structural and nonoxygen-sensitive subunit that is required for synthesis of the active form of HIF-1 $\alpha$ [88]. Both $\alpha$ and $\beta$ subunits have a Per-ARNT-Sim (PAS) domain, which is involved in HIF- $1 \alpha$ heterodimerization and DNA binding $[87,88]$. The C-terminal side of HIF- $1 \alpha$ contains two domains for interaction with the cAMP response elementbinding protein- (CREB-) binding protein (CBP) and $\mathrm{p} 300$ $(\mathrm{CBP} / \mathrm{p} 300)$ [87]. As shown in Figure 2, CBP/p300 recognizes the hypoxia-response element (HRE) in target genes; the products of these genes include cytokines, growth factors, glucose-transporter genes (GLUT1 and GLUT2), and angiogenic genes (VEGF) that are needed for the adaptation to hypoxia $[89,90]$.

(2) Stabilization and Destabilization of HIF- $1 \alpha$. HIF- $1 \alpha$ is expressed in all cells, has a half-life of $\sim 1 \mathrm{~min}$, and is regulated via 4-hydroxylation of proline residues (402 or 564) by PHDs, which is oxygen dependent and, in presence of sufficient oxygen, hydroxylates these proline residues [87]. Asparagine-803 residue of the $\alpha$ subunit of HIF- $1 \alpha$ is hydroxylated by the factor-inhibiting hypoxia-inducible factor (FIH) [87]. The 4-hydroxyprolyl HIF- $1 \alpha$ binds to the $\beta$-domain of von Hippel-Lindau tumor suppressor protein (pVHL) by a hydrogen bond; then pVHL (from its $\alpha$ domain) binds to Elongin C/B (E3 ligase complex) proteins and induces polyubiquitination of HIF- $1 \alpha$ [91]. Ubi-HIF$1 \alpha$ is considered a signal for degradation in $26 \mathrm{~S}$ proteasomes (Figure 3) [91]. PHD can hydroxylate the proline residues at several sites of HIF- $1 \alpha$, but only some of them (P402 and P564) react with pVHL and cause 26S degradation; 


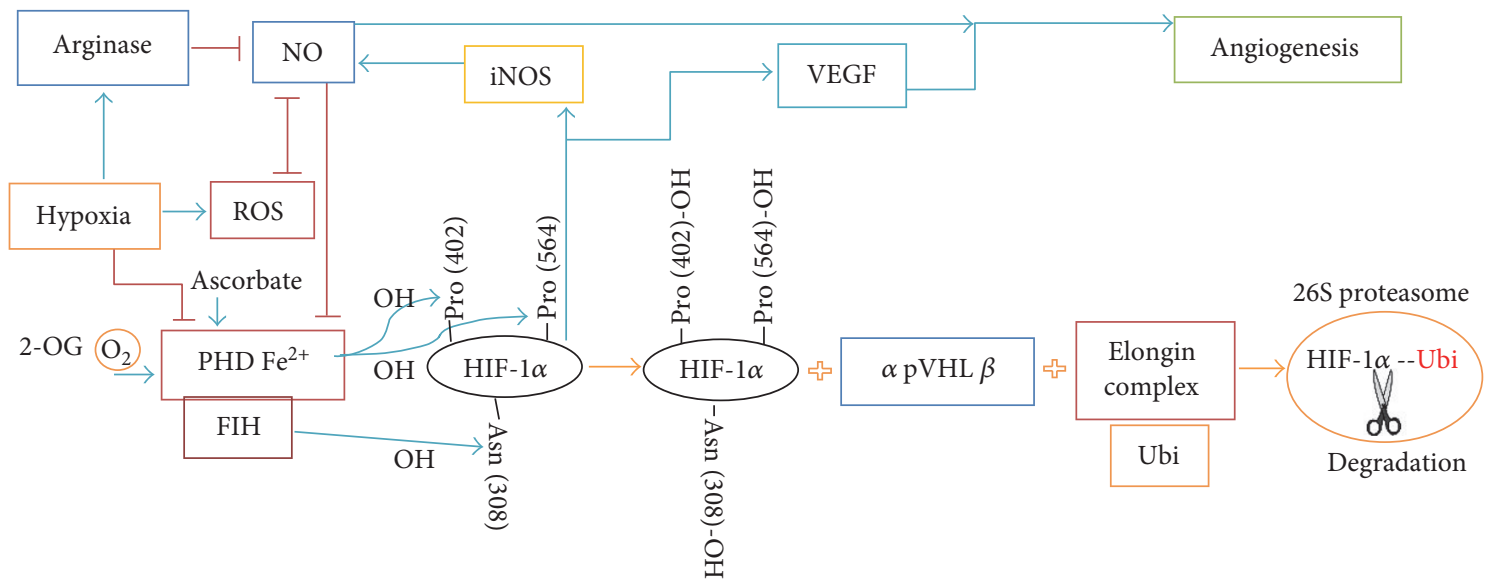

$\longrightarrow$ Stimulation

Figure 3: Hypoxia-inducible factor- $1 \alpha$ (HIF-1 $\alpha$ ) degradation/stabilization. Inhibition of prolyl hydroxylase domain (PHD) enzymes by hypoxia and nitric oxide (NO) leads to stabilization of HIF-1 $\alpha$. Hypoxia upregulates the arginase enzyme; thus, the substrate of NO synthase (NOS), arginine, is reduced and NO production is decreased. Furthermore, hypoxia can induce production of ROS (superoxide anion). The bioavailability of ROS and NO is regulated by each other. HIF- $1 \alpha$ upregulates inducible NOS (iNOS), which produces NO. NO inhibits PHD and stabilizes HIF-1 $\alpha$; NO can also contribute to angiogenesis through vascular endothelial growth factor (VEGF), which is upregulated by HIF-1 $\alpha$. Asn: asparagine; Pro: proline; pVHL: Von Hippel-Lindau tumor suppressor protein.

interestingly, the full-length HIF-1 $\alpha$ that contains proline to alanine amino acid sequences, P402A/P564A, is resistant to PHD- and PVHL-mediated degradation [92].

(3) The Effect of Oxygen and NO on HIF-1 $\alpha$ Stabilization. As shown in Figure 3, the activation of PHD requires oxygen, 2oxoglutarate (2-OG), and binding to $\mathrm{Fe}^{+2}$; this activation is controlled by NO and oxygen levels [91]. In hypoxia, mitochondrial consume oxygen and low oxygen levels inactivate PHD; the hydroxylation of the $\alpha$ subunit of HIF- $1 \alpha$ is therefore attenuated and binds to the $\beta$ subunit to produce the active form of HIF- $1 \alpha$ [91], which is then translocated to the nucleus and binds to $\mathrm{CBP} / \mathrm{p} 300$; the complex then binds to HRE and other coactivators and controls the transcription of the genes needed for hypoxia adaptation; decreased FIH and production of dehydroxylated asparagine 803 residue are necessary for the binding of HIF- $1 \alpha$ and $\mathrm{CBP} / \mathrm{p} 300[87,91]$. In addition, hypoxia stimulates inducible NO synthase (iNOS), and NO overproduction inhibits oxygen consumption by mitochondria; this generates a situation similar to normoxia, where oxygen level is not too low to inactivate the PHD and HIF- $1 \alpha$ is then degraded in the proteasomes [93, 94]; this mechanism may explain the decreases in HIF- $1 \alpha$ after the first exposure to hypoxia.

(4) Other Factors That Influence HIF-1 $\alpha$ Stabilization. The receptor for activated $\mathrm{C}$ kinase 1 (RACK1) competes with heat shock protein 90 (HSP90) to bind to HIF-1 $\alpha$. RACK1 causes polyubiquitination of HIF- $1 \alpha$ by binding to Elongin $\mathrm{C}$ and ultimately producing Ubi-HIF- $1 \alpha$, which is degraded by proteasomes [92]; RACK1-induced degradation of HIF$1 \alpha$ is independent of oxygen, pVHL, and PHD. HSP90
TABLE 3: Factors influencing HIF- $1 \alpha$ stabilization.

\begin{tabular}{lccc}
\hline Effectors & $\begin{array}{c}\text { HIF-1 } \alpha \\
\text { stabilizer }\end{array}$ & $\begin{array}{c}\text { HIF-1 } \alpha \\
\text { destabilizer }\end{array}$ & References \\
\hline Oxygen & & $\checkmark$ & {$[87]$} \\
2-OG (2-oxoglutarate) & $\checkmark$ & $\checkmark$ & {$[87]$} \\
Hypoxia & & $\checkmark^{*}$ & {$[87]$} \\
Hyperoxia & & $\checkmark$ & {$[95]$} \\
iNOS-derived NO & & $\checkmark$ & {$[94]$} \\
RACK1 & $\checkmark$ & & {$[92]$} \\
HSP90 & $\checkmark$ & & {$[81,82]$} \\
ROS & & & \\
\hline
\end{tabular}

HIF- $1 \alpha$ : hypoxia-inducible factor- $1 \alpha$; HSP90: heat shock protein 90 ; iNOS: inducible nitric oxide synthase; RACK1: receptor for activated C kinase 1; ROS: reactive oxygen species.

${ }^{*} \mathrm{HIF}-1 \alpha$ gene expression increases in the first week of hyperoxia exposure and is restored to near normal values in prolonged hyperoxia exposure in weeks 2-3.

competes with RACK1 to bind to residues $81-200$ in the PAS-A subdomain of HIF- $1 \alpha$; the binding of HSP90 to HIF- $1 \alpha$ leads to the stabilization of HIF- $1 \alpha$ by preventing the binding of RACK1 to HIF-1 $\alpha$ [92]. Table 3 shows the factors that influence HIF-1 $\alpha$ stabilization.

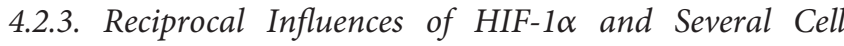 Pathways and Signals}

(1) The Effects of HIF-1 $\alpha$ on the Metabolism of Lipids and Carbohydrates. HIF- $1 \alpha$ induces glycolysis (glucose fermentation independent of Krebs cycle) in adipocytes both directly by the activation of enolase and 6-phosphofructokinase and indirectly by the activation of 6-phosphofructokinase, 
fructose-2, 6-biphosphatase, and aldolase C; HIF-1 $\alpha$ is also directly involved in the metabolism of lipids (by activation of leptin) and angiogenesis (by induction of VEGF), as well as indirectly disrupting insulin signaling [96]. In HIF- $1 \alpha$ knockout mice, fed on a high-fat diet, fat mass was decreased, adiponectin induced, and these mice did not develop either obesity or insulin resistance [97].

(2) The Effect of HIF-1 $\alpha$ on BAT and WAT. HIF- $1 \alpha$ may have a dual role in the development of obesity-related disorders, because of its different functions in WAT and BAT cells; Zhang et al. reported that increased HIF- $1 \alpha$ induces thermogenesis in BATs by increasing both VEGF-dependent angiogenesis and mitochondria biogenesis; on the other hand, increased HIF- $1 \alpha$ increases fibrosis and inflammation in WATs [98]. However, it has been reported that the vascular network is diminished in both BAT and WAT in dietinduced obesity; decreased capillary density is higher in BAT than in WAT, leading to BAT whitening; that is, BAT shows the WAT phenotype [99]. Interestingly, cold induces VEGF expression independent of hypoxia and HIF- $1 \alpha$ in both WAT and BAT cells by PPAR $\gamma$ coactivator 1- $\alpha$ $(\mathrm{PGC}-1 \alpha)$ [100].

Collectively, the overall function of HIF- $1 \alpha$ is to adjust cell metabolism on low oxygen consumption. The use of hyperoxia or natural nitrate-containing vegetables may be a strategy to reverse obesity disorders; in support of the nitrate intervention, $\mathrm{NO}$ has a positive effect on vascular and capillary tone [101] and, unlike BAT whitening factors, causes WAT browning $[102,103]$.

4.2.4. NO Bioavailability in Hypoxia. NO contributes to vasodilation, vascular remodeling, angiogenesis, and glucose metabolism, as well as playing a protective role in cardiovascular disease $[51,75,104,105]$. NO is produced by eNOS via the oxygen-dependent pathway, a route which is disabled in a hypoxic state, where NO would be produced via the nitratenitrite-NO pathway, to maintain NO bioavailability [106]. Additionally, NO has a very low half-life $(\sim 0.05-1.18 \mathrm{~ms})$ [107] and acts locally as an autocrine or paracrine factor, whereas nitrite and nitrate act as endocrine hormones and NO reservoirs [108-110] due to their longer half-lives (110 s and 5-8h, resp.) [107]. Furthermore, arginine is the common substrate for both arginase and NOS and the increase of arginase activity reduces the arginine needed for NO production by NOS, a status which can cause endothelial dysfunction $[105,111]$. Interestingly, arginase is upregulated by hypoxia [111], TNF- $\alpha$, and superoxide anion (derived from uncoupled eNOS) [112], all occurring in obesity and can act together increasing the susceptibility to diabetes in obese individuals. In vitro hypoxia decreases the phosphorylation of serine-1177 and increases the phosphorylation of threonine-495 in eNOS, reducing its activity; furthermore, hypoxia also decreases arginine transporter [111, 113, 114]. In summary, hypoxia decreases NO bioavailability and causes endothelial dysfunction.

4.2.5. NO and Insulin Resistance. Exogenously delivered NO (sodium nitroprusside as a NO donor) stimulates uptake and transendothelial transport (TET) of insulin by inhibition of protein tyrosine phosphatase $1 \mathrm{~B}$ (PTP1B) via S-nitrosylation; PTP1B dephosphorylates the IRS-1 and IRS-2 tyrosines, as well as inhibiting insulin signaling and TET [115]. Insulin resistance increases mitogen-activated protein kinase (MAPK) activity via blocking phosphatidylinositol 3-kinase (PI3K). PI3K increases eNOS activity and NO production, thereby decreasing insulin resistance; in addition, increased MAPK activity leads to vasoconstriction through endothelin1 [116]. Thus, insulin resistance can lead to endothelial dysfunction; reciprocally, endothelial dysfunction can cause insulin resistance [117].

Despite previous reports on the carcinogenic effect of dietary nitrate/nitrite $[118,119]$, no association has been found between nitrate/nitrite and the risk of cancer in some later studies [103, 120, 121]. Inorganic nitrite increases blood flow of pancreatic islets and stimulates insulin secretion [122]. To support the benefits of nitrate intervention, Hezel et al. have demonstrated that long-term dietary nitrate (17 months, NaNO3: $1 \mathrm{mmol} / \mathrm{L}$ ) improves the response of insulin and concluded that nitrate has no harmful effects on the health of mice [103]. As shown in Figure 1, NO and nitrate can also mimic insulin functions and induce GLUT4 translocation to the cell membrane via nitrosylation of GLUT4 [51].

Elevated free fatty acids in obesity and hypoxia [55] induce inhibitor of kappa $\mathrm{B}(\mathrm{I} \kappa \mathrm{B})$ kinase $\beta(\mathrm{IKK} \beta)$, which phosphorylates serine residues of IRS-1 and interrupts IRS1/PI3k/Akt-dependent eNOS activity that causes NO depletion and impairment of insulin signaling [123]. Free fatty acids also interfere with NO production and insulin signaling by other ways including activating Toll-like receptors (TLRs), in particular TLR4, as shown in Figure 1 [123, 124].

To summarize, obesity and hypoxia cause oxidative stress and NO depletion, leading to endothelial dysfunction, and consequent obesity disorders. Inorganic nitrate/nitrite apart from replenishing decreased NO bioavailability has antioxidant properties; inorganic nitrite reduces superoxide anion bioavailability and iNOS activity $[11,125]$. Nitrate administration decreases malondialdehyde (a marker of lipid peroxidation) concentrations and urine concentrations of class VI F2isoprostanes and 8-hydroxy-2-deoxyguanosine [126, 127]. In addition, nitrite can decrease the formation of vascular ROS, perhaps, by the diversion of electrons away from oxygen [106].

\section{Advantages and Disadvantages of Hyperoxia Intervention}

Normobaric and hyperbaric oxygen therapies (NBOT and HBOT, resp.) have been used in medicine. NBOT has beneficial therapeutic effects on severe acute ischemic stroke [128], and HBOT is therapeutically used in cardiovascular diseases, sleep apnea, wound healing, and management of some tumors [129-131]. Quintero et al. [5] were the first to show that hyperoxia $\left(95 \% \mathrm{O}_{2}, 24 \mathrm{~h}\right)$ can increase ROS and proinflammatory adipokines in 3T3-L1 adipocytes; they also showed that hyperoxia upregulates PPAR $\gamma$ that may indirectly have positive effects on insulin sensitivity $[5,9]$. Treatment with HBOT (2 atmospheres, 2 h/day, 6 times/week, for 5 weeks) increases insulin sensitivity [132]. NBOT $\left(60 \% \mathrm{O}_{2}\right.$, 
3 days) increases adipocyte survival and regeneration in animal models of fat grafting [133]. Hyperoxia $\left(35 \% \mathrm{O}_{2}\right)$ can reverse the toxic effects of a high-dose glucose $(33.3 \mathrm{mM})$ on INS1 $\beta$-cells and restore insulin secretion [134]. Chronic moderate hyperoxia $\left(50 \% \mathrm{O}_{2}\right.$, for 3 weeks) in male C57BL mice slowed body weight gain and decreased VEGF expression; it however increased HIF- $1 \alpha$ level during the first week and decreased it after a prolonged exposure [95]. In monosodium glutamate-treated mice, HBOT (2.5 atmospheres, $60 \mathrm{~min} / \mathrm{d}$, for 4 weeks with 2 weeks interval) decreased body weight and increased oxidative stress [7]. Furthermore, hyperoxia $\left(36 \% \mathrm{O}_{2}\right.$ for $3 \mathrm{~h}$ daily) in obese type II diabetic rats led to decline in fasting glucose, HbAlc, and the size of adipocytes and increase in metabolic capacity in muscle [135]. A review conducted on the effects of HBOT on traumatic brain injury concluded that HBOT has neuroprotective effects via improvement of tissue oxygenation and cellular metabolism and anti-inflammatory and antiapoptotic properties [136]; hyperoxia (2.4 atmospheres, $90 \mathrm{~min}$ ) also decreases inflammation in an animal model of inflammatory pain [137]. Hyperoxia depletes 5,6,7,8-tetrahydrobiopterin (BH4) cofactor in the neonatal retina [8]. Bioavailability of $\mathrm{BH} 4$ is needed for the normal eNOS function, as $\mathrm{BH} 4$ depletion can uncouple eNOS, which produces superoxide anion, thereby decreasing NO production [138]. Some of the other adverse effects of hyperoxia such as inflammation and oxidative stress have been reported [7], as well as anti-inflammatory effects [136, 137]. It is interesting to mention that oxidative stress linked to hyperoxia can have a therapeutic action [139]. Overall, it seems that hyperoxia has important and undeniable advantages, but its safe dose and exposure duration need to be clearly defined.

\section{Conclusions and Perspectives}

Obesity is a chronic hypoxic state, which causes several deleterious changes such as adipose tissue dysfunction, insulin resistance, inflammation, and organ damage, changes which can lead to other metabolic disorders including cardiovascular disease and diabetes. In recent years, to prevent the adverse effects of obesity, some interventions have been suggested, such as drugs, exercise, and healthier diet patterns [140-142]. Although some researchers indicate that high altitudes and hypoxia can lead to weight loss and lower risk of metabolic syndrome [143, 144], these might also have some adverse effects [145] such as decrease in muscle mass instead of fat mass, inflammation, macrophages infiltration, and insulin resistance $[146,147]$, indicating that not all individuals can adhere to these conditions. Hyperoxia has beneficial effects and can reverse the aforementioned hypoxic status, for example, insulin sensitivity and wound healing [146, 148, 149]. Hyperoxia could be considered as a new strategy for the management of obesity and type 2 diabetes. Exposure to higher doses of oxygen, however, could produce adverse effects [150-152] including eNOS inhibition and increased ROS, both of which could contribute to the development of metabolic disorders and adipocyte dysfunction $[153,154]$. Both acute and chronic exposures to hyperoxia have positive effects on carbohydrate metabolism $[132,135]$, and they can decrease adipocyte size $[7,135]$. Nonetheless, there are some differences between the types of exposures; for example, acute exposure has antiinflammatory effects, while chronic exposure has the opposite effects $[5,9,137]$. Furthermore, the effects of hyperoxia on oxidative stress and VEGF have been reported in the chronic treatment $[7,95]$. In addition, there is a report suggesting that hyperoxia during the first week of treatment increased HIF- $1 \alpha$ and HIF- $2 \alpha$ levels, which were restored to near normal values at 2 to 3 weeks of exposure [95]. It has also been shown that hyperoxia inhibits HIF- $1 \alpha$ protein expression and DNA-binding activity, in rat INS-1 $\beta$ cells [134]. Further studies are needed to elucidate the acute and chronic effects of hyperoxia.

Recent data support the beneficial effects of a nutritional-based nitrate/nitrite therapy in obesity and diabetes $[108,155]$. Nitrate has also antioxidant properties [11], and it can restore NO depletion induced by hyperoxia. Therefore, for the management of obesity, it seems reasonable to combine hyperoxia and nitrate. To the best of our knowledge, there is no study to address the effect of this combination therapy to manage obesity/diabetes, warranting the need for evaluating the effects of hyperoxia with different durations and oxygen pressures $[7,156,157]$, viz. on hyperbaric versus normobaric hyperoxia, simultaneously with nitrate intervention.

\section{Ethical Approval}

The proposal for this study was approved by the ethics committee of our institute.

\section{Conflicts of Interest}

No competing interests are declared by the authors.

\section{Authors' Contributions}

The study was conceived by all authors. Reza Norouzirad and Asghar Ghasemi drafted the manuscript; Reza Norouzirad, Asghar Ghasemi, and Pedro González-Muniesa critically revised the manuscript. All of the authors read and approved the final manuscript.

\section{Acknowledgments}

The authors acknowledge Ms. Niloofar Shiva, an academic faculty member of Research Institute for Endocrine Sciences, for critical editing of the English grammar and syntax of the manuscript. This study has been extracted from a part of the thesis written by Reza Norouzirad, Ph.D. candidate, Endocrine Physiology Research Center, Research Institute for Endocrine Sciences, Shahid Beheshti University of Medical Sciences, and was funded and supported by the Endocrine Physiology Research Center, Research Institute for Endocrine Sciences, Shahid Beheshti University of Medical Sciences, Tehran, Iran.

\section{References}

[1] B. Zhou, Y. Lu, K. Hajifathalian et al., "Worldwide trends in diabetes since 1980: a pooled analysis of 751 population- 
based studies with 4.4 million participants," Lancet, vol. 387, no. 10027, pp. 1513-1530, 2016.

[2] A. Guilherme, J. V. Virbasius, V. Puri, and M. P. Czech, “Adipocyte dysfunctions linking obesity to insulin resistance and type 2 diabetes," Nature Reviews Molecular Cell Biology, vol. 9, no. 5, pp. 367-377, 2008.

[3] R. E. Duncan, M. Ahmadian, K. Jaworski, E. Sarkadi-Nagy, and H. S. Sul, "Regulation of lipolysis in adipocytes," Annual Review of Nutrition, vol. 27, pp. 79-101, 2007.

[4] N. Hosogai, A. Fukuhara, K. Oshima et al., "Adipose tissue hypoxia in obesity and its impact on adipocytokine dysregulation," Diabetes, vol. 56, no. 4, pp. 901-911, 2007.

[5] P. Quintero, P. Gonzalez-Muniesa, D. F. Garcia-Diaz, and J. A. Martinez, "Effects of hyperoxia exposure on metabolic markers and gene expression in 3T3-L1 adipocytes," Journal of Physiology and Biochemistry, vol. 68, no. 4, pp. 663-669, 2012.

[6] P. Gonzalez-Muniesa, L. Garcia-Gerique, P. Quintero, S. Arriaza, A. Lopez-Pascual, and J. A. Martinez, "Effects of hyperoxia on oxygen-related inflammation with a focus on obesity," Oxidative Medicine and Cellular Longevity, vol. 2015, Article ID 8957827, p. 11, 2015.

[7] K. Tsuneyama, Y. C. Chen, M. Fujimoto et al., "Advantages and disadvantages of hyperbaric oxygen treatment in mice with obesity hyperlipidemia and steatohepatitis," The Scientific World Journal, vol. 11, pp. 2124-2135, 2011.

[8] K. S. Edgar, N. Matesanz, T. A. Gardiner, Z. S. Katusic, and D. M. McDonald, "Hyperoxia depletes (6R)-5,6,7,8-tetrahydrobiopterin levels in the neonatal retina: implications for nitric oxide synthase function in retinopathy," The American Journal of Pathology, vol. 185, no. 6, pp. 1769-1782, 2015.

[9] P. Quintero, P. Gonzalez-Muniesa, and J. A. Martinez, "Influence of different oxygen supply on metabolic markers and gene response in murine adipocytes," Journal of Biological Regulators and Homeostatic Agents, vol. 26, no. 3, pp. 379388, 2012.

[10] A. Ghasemi and S. Zahediasl, "Potential therapeutic effects of nitrate/nitrite and type 2 diabetes mellitus," International Journal of Endocrinology and Metabolism, vol. 11, no. 2, pp. 63-64, 2013.

[11] Z. Bahadoran, A. Ghasemi, P. Mirmiran, F. Azizi, and F. Hadaegh, "Beneficial effects of inorganic nitrate/nitrite in type 2 diabetes and its complications," Nutrition \& Metabolism, vol. 12, no. 1, p. 16, 2015.

[12] S. Keipert and M. Jastroch, "Brite/beige fat and UCP1 - is it thermogenesis?" Biochimica et Biophysica Acta, vol. 1837, no. 7, pp. 1075-1082, 2014.

[13] B. Cannon and J. Nedergaard, "Brown adipose tissue: function and physiological significance," Physiological Reviews, vol. 84, no. 1, pp. 277-359, 2004.

[14] V. Peirce, S. Carobbio, and A. Vidal-Puig, "The different shades of fat," Nature, vol. 510, no. 7503, pp. 76-83, 2014.

[15] J. Wu, P. Bostrom, L. M. Sparks et al., "Beige adipocytes are a distinct type of thermogenic fat cell in mouse and human," Cell, vol. 150, no. 2, pp. 366-376, 2012.

[16] M. Lafontan, "Adipose tissue and adipocyte dysregulation," Diabetes \& Metabolism, vol. 40, no. 1, pp. 16-28, 2014.

[17] N. Alexopoulos, D. Katritsis, and P. Raggi, "Visceral adipose tissue as a source of inflammation and promoter of atherosclerosis," Atherosclerosis, vol. 233, no. 1, pp. 104-112, 2014.
[18] K. Fujita, H. Nishizawa, T. Funahashi, I. Shimomura, and M. Shimabukuro, "Systemic oxidative stress is associated with visceral fat accumulation and the metabolic syndrome," Circulation Journal: Official Journal of the Japanese Circulation Society, vol. 70, no. 11, pp. 1437-1442, 2006.

[19] P. Trayhurn, "Hypoxia and adipose tissue function and dysfunction in obesity," Physiological Reviews, vol. 93, no. 1, pp. 1-21, 2013.

[20] C. H. Saely, K. Geiger, and H. Drexel, "Brown versus white adipose tissue: a mini-review," Gerontology, vol. 58, no. 1, pp. 15-23, 2012.

[21] T. B. Walden, I. R. Hansen, J. A. Timmons, B. Cannon, and J. Nedergaard, "Recruited vs. nonrecruited molecular signatures of brown, "brite," and white adipose tissues," The American Journal of Physiology - Endocrinology and Metabolism, vol. 302, no. 1, pp. E19-E31, 2012.

[22] K. L. Spalding, E. Arner, P. O. Westermark et al., "Dynamics of fat cell turnover in humans," Nature, vol. 453, no. 7196, pp. 783-787, 2008.

[23] S. A. Nagel, M. Keuper, I. Zagotta et al., "Up-regulation of Bcl-2 during adipogenesis mediates apoptosis resistance in human adipocytes," Molecular and Cellular Endocrinology, vol. 382, no. 1, pp. 368-376, 2014.

[24] P. Fischer-Posovszky, H. Tornqvist, K. M. Debatin, and M. Wabitsch, "Inhibition of death-receptor mediated apoptosis in human adipocytes by the insulin-like growth factor I (IGF-I)/IGF-I receptor autocrine circuit," Endocrinology, vol. 145, no. 4, pp. 1849-1859, 2004.

[25] F. J. Tinahones, L. Coin Araguez, M. Murri et al., "Caspase induction and BCL2 inhibition in human adipose tissue: a potential relationship with insulin signaling alteration," Diabetes Care, vol. 36, no. 3, pp. 513-521, 2013.

[26] K. J. Strissel, Z. Stancheva, H. Miyoshi et al., "Adipocyte death, adipose tissue remodeling, and obesity complications," Diabetes, vol. 56, no. 12, pp. 2910-2918, 2007.

[27] S. Gheibi, F. Bakhtiarzadeh, S. Jeddi, K. Farrokhfall, H. Zardooz, and A. Ghasemi, "Nitrite increases glucosestimulated insulin secretion and islet insulin content in obese type 2 diabetic male rats," Nitric Oxide: Biology and Chemistry/Official Journal of the Nitric Oxide Society, vol. 64, pp. 39-51, 2017.

[28] C. Rammos, U. B. Hendgen-Cotta, J. Pohl et al., "Modulation of circulating macrophage migration inhibitory factor in the elderly," BioMed Research International, vol. 2014, Article ID 582586, p. 8, 2014.

[29] L. Briscini, C. Tonello, L. Dioni, M. O. Carruba, and E. Nisoli, "Bcl-2 and Bax are involved in the sympathetic protection of brown adipocytes from obesity-linked apoptosis," FEBS Letters, vol. 431, no. 1, pp. 80-84, 1998.

[30] E. Nisoli, L. Briscini, C. Tonello, C. De Giuli-Morghen, and M. O. Carruba, "Tumor necrosis factor-alpha induces apoptosis in rat brown adipocytes," Cell Death and Differentiation, vol. 4, no. 8, pp. 771-778, 1997.

[31] L. Hellstrom and S. Reynisdottir, "Influence of heredity for obesity on adipocyte lipolysis in lean and obese subjects," International Journal of Obesity and Related Metabolic Disorders : Journal of the International Association for the Study of Obesity, vol. 24, no. 3, pp. 340-344, 2000.

[32] I. Briaud, J. S. Harmon, C. L. Kelpe, V. B. G. Segu, and V. Poitout, "Lipotoxicity of the pancreatic $\beta$-cell is associated with glucose-dependent Esterification of fatty acids 
into neutral lipids," Diabetes, vol. 50, no. 2, pp. 315-321, 2001.

[33] J. O. Ebbert and M. D. Jensen, "Fat depots, free fatty acids, and dyslipidemia," Nutrients, vol. 5, no. 2, pp. 498-508, 2013.

[34] J. Yin, Z. Gao, Q. He, D. Zhou, Z. Guo, and J. Ye, "Role of hypoxia in obesity-induced disorders of glucose and lipid metabolism in adipose tissue," American Journal of Physiology Endocrinology and Metabolism, vol. 296, no. 2, pp. E333-E342, 2009.

[35] L. Best, E. Jarman, and P. D. Brown, "A dual action of saturated fatty acids on electrical activity in rat pancreatic betacells. Role of volume-regulated anion channel and KATP channel currents," The Journal of Physiology, vol. 589, Part 6, pp. 1307-1316, 2011.

[36] P. Isakson, A. Hammarstedt, B. Gustafson, and U. Smith, "Impaired preadipocyte differentiation in human abdominal obesity: role of Wnt, tumor necrosis factor-alpha, and inflammation," Diabetes, vol. 58, no. 7, pp. 1550-1557, 2009.

[37] D. Vara, C. Morell, N. Rodriguez-Henche, and I. DiazLaviada, "Involvement of PPARgamma in the antitumoral action of cannabinoids on hepatocellular carcinoma," Cell Death \& Disease, vol. 4, no. 5, article e618, 2013.

[38] M. Cortez, L. S. Carmo, M. M. Rogero, P. Borelli, and R. A. Fock, "A high-fat diet increases IL-1, IL-6, and TNF-alpha production by increasing NF-kappaB and attenuating PPAR-gamma expression in bone marrow mesenchymal stem cells," Inflammation, vol. 36, no. 2, pp. 379-386, 2013.

[39] S. P. Weisberg, D. McCann, M. Desai, M. Rosenbaum, R. L. Leibel, and A. W. Ferrante, "Obesity is associated with macrophage accumulation in adipose tissue," The Journal of Clinical Investigation, vol. 112, no. 12, pp. 1796-1808, 2003.

[40] C. N. Lumeng, J. L. Bodzin, and A. R. Saltiel, "Obesity induces a phenotypic switch in adipose tissue macrophage polarization," The Journal of Clinical Investigation, vol. 117, no. 1, pp. 175-184, 2007.

[41] P. A. Kern, G. B. Di Gregorio, T. Lu, N. Rassouli, and G. Ranganathan, "Adiponectin expression from human adipose tissue: relation to obesity, insulin resistance, and tumor necrosis factor-alpha expression," Diabetes, vol. 52, no. 7, pp. 1779-1785, 2003.

[42] Z. V. Wang and P. E. Scherer, "Adiponectin, the past two decades," Journal of Molecular Cell Biology, vol. 8, no. 2, pp. 93-100, 2016.

[43] D. M. Schulte, N. Muller, K. Neumann et al., "Pro-inflammatory wnt5a and anti-inflammatory sFRP5 are differentially regulated by nutritional factors in obese human subjects," PloS One, vol. 7, no. 2, article e32437, 2012.

[44] T. Enomoto, K. Ohashi, R. Shibata et al., "Adipolin/C1qdc2/ CTRP12 protein functions as an adipokine that improves glucose metabolism," The Journal of Biological Chemistry, vol. 286, no. 40, pp. 34552-34558, 2011.

[45] D. K. Lee, S. R. George, and B. F. O'Dowd, "Unravelling the roles of the apelin system: prospective therapeutic applications in heart failure and obesity," Trends in Pharmacological Sciences, vol. 27, no. 4, pp. 190-194, 2006.

[46] M. V. Heinonen, A. K. Purhonen, P. Miettinen et al., "Apelin, orexin-A and leptin plasma levels in morbid obesity and effect of gastric banding," Regulatory Peptides, vol. 130, no. 1-2, pp. 7-13, 2005.
[47] M. Sawane, K. Kajiya, H. Kidoya, M. Takagi, F. Muramatsu, and N. Takakura, "Apelin inhibits diet-induced obesity by enhancing lymphatic and blood vessel integrity," Diabetes, vol. 62, no. 6, pp. 1970-1980, 2013.

[48] R. M. Evans, G. D. Barish, and Y. X. Wang, "PPARs and the complex journey to obesity," Nature Medicine, vol. 10, no. 4, pp. 355-361, 2004.

[49] A. Jamroz-Wisniewska, A. Gertler, G. Solomon, M. E. Wood, M. Whiteman, and J. Beltowski, "Leptin-induced endothelium-dependent vasorelaxation of peripheral arteries in lean and obese rats: role of nitric oxide and hydrogen sulfide," PloS One, vol. 9, no. 1, article e86744, 2014.

[50] C. M. Steppan, S. T. Bailey, S. Bhat et al., "The hormone resistin links obesity to diabetes," Nature, vol. 409, no. 6818 , pp. 307-312, 2001.

[51] H. Jiang, A. C. Torregrossa, A. Potts et al., "Dietary nitrite improves insulin signaling through GLUT4 translocation," Free Radical Biology \& Medicine, vol. 67, pp. 51-57, 2014.

[52] M. F. White, "Insulin signaling in health and disease," Science, vol. 302, no. 5651, pp. 1710-1711, 2003.

[53] C. Regazzetti, P. Peraldi, T. Gremeaux et al., "Hypoxia decreases insulin signaling pathways in adipocytes," Diabetes, vol. 58, no. 1, pp. 95-103, 2009.

[54] C. M. Taniguchi, E. C. Finger, A. J. Krieg et al., "Cross-talk between hypoxia and insulin signaling through $\mathrm{Phd} 3 \mathrm{regu}-$ lates hepatic glucose and lipid metabolism and ameliorates diabetes," Nature Medicine, vol. 19, no. 10, pp. 1325-1330, 2013.

[55] A. Priyanka, G. Sindhu, G. L. Shyni, M. R. Preetha Rani, V. M. Nisha, and K. G. Raghu, "Bilobalide abates inflammation, insulin resistance and secretion of angiogenic factors induced by hypoxia in 3T3-L1 adipocytes by controlling NF-kappaB and JNK activation," International Immunopharmacology, vol. 42, pp. 209-217, 2017.

[56] L. Simon-Szabo, M. Kokas, J. Mandl, G. Keri, and M. Csala, "Metformin attenuates palmitate-induced endoplasmic reticulum stress, serine phosphorylation of IRS-1 and apoptosis in rat insulinoma cells," PloS One, vol. 9, no. 6, article e97868, 2014.

[57] J. Hirosumi, G. Tuncman, L. Chang et al., "A central role for JNK in obesity and insulin resistance," Nature, vol. 420, no. 6913, pp. 333-336, 2002.

[58] S. T. Ferreira, J. R. Clarke, T. R. Bomfim, and F. G. De Felice, "Inflammation, defective insulin signaling, and neuronal dysfunction in Alzheimer's disease," Alzheimer's \& Dementia : The Journal of the Alzheimer's Association, vol. 10, 1 Supplement, pp. S76-S83, 2014.

[59] X. Ma, F. Fang, M. Song, and S. Ma, "The effect of isoliquiritigenin on learning and memory impairments induced by high-fat diet via inhibiting TNF-alpha/JNK/IRS signaling," Biochemical and Biophysical Research Communications, vol. 464, no. 4, pp. 1090-1095, 2015.

[60] N. Ouchi, K. Ohashi, R. Shibata, and T. Murohara, "Adipocytokines and obesity-linked disorders," Nagoya Journal of Medical Science, vol. 74, no. 1-2, pp. 19-30, 2012.

[61] X. Zhang, A. Xu, S. K. Chung et al., "Selective inactivation of c-Jun NH2-terminal kinase in adipose tissue protects against diet-induced obesity and improves insulin sensitivity in both liver and skeletal muscle in mice," Diabetes, vol. 60, no. 2, pp. 486-495, 2011. 
[62] C. Leloup, C. Tourrel-Cuzin, C. Magnan et al., "Mitochondrial reactive oxygen species are obligatory signals for glucose-induced insulin secretion," Diabetes, vol. 58, no. 3, pp. 673-681, 2009.

[63] K. Loh, H. Deng, A. Fukushima et al., "Reactive oxygen species enhance insulin sensitivity," Cell Metabolism, vol. 10, no. 4, pp. 260-272, 2009.

[64] S. Di Meo, S. Iossa, and P. Venditti, "Skeletal muscle insulin resistance: role of mitochondria and other ROS sources," Journal of Endocrinology, vol. 233, no. 1, pp. R15-R42, 2017.

[65] F. McMurray, D. A. Patten, and M. E. Harper, "Reactive oxygen species and oxidative stress in obesity-recent findings and empirical approaches," Obesity, vol. 24, no. 11, pp. 23012310, 2016.

[66] T. Yu, J. L. Robotham, and Y. Yoon, "Increased production of reactive oxygen species in hyperglycemic conditions requires dynamic change of mitochondrial morphology," Proceedings of the National Academy of Sciences of the United States of America, vol. 103, no. 8, pp. 2653-2658, 2006.

[67] A. Boveris, L. B. Valdez, T. Zaobornyj, and J. Bustamante, "Mitochondrial metabolic states regulate nitric oxide and hydrogen peroxide diffusion to the cytosol," Biochimica et Biophysica Acta, vol. 1757, no. 5-6, pp. 535-542, 2006.

[68] G. P. Bienert, J. K. Schjoerring, and T. P. Jahn, "Membrane transport of hydrogen peroxide," Biochimica et Biophysica Acta, vol. 1758, no. 8, pp. 994-1003, 2006.

[69] E. T. Chouchani, L. Kazak, M. P. Jedrychowski et al., "Mitochondrial ROS regulate thermogenic energy expenditure and sulfenylation of UCP1," Nature, vol. 532, no. 7597, pp. 112-116, 2016.

[70] T. J. Biden, E. Boslem, K. Y. Chu, and N. Sue, "Lipotoxic endoplasmic reticulum stress, $\beta$ cell failure, and type 2 diabetes mellitus," Trends in Endocrinology \& Metabolism, vol. 25, no. 8, pp. 389-398, 2014, http://dx.doi.org/10.1016/j.tem 2014.02.003

[71] I. Tabas and D. Ron, "Integrating the mechanisms of apoptosis induced by endoplasmic reticulum stress," Nature Cell Biology, vol. 13, no. 3, pp. 184-190, 2011.

[72] J. P. Ye, Z. G. Gao, J. Yin, and Q. He, "Hypoxia is a potential risk factor for chronic inflammation and adiponectin reduction in adipose tissue of ob/ob and dietary obese mice," The American Journal of Physiology - Endocrinology and Metabolism, vol. 293, no. 4, pp. E1118-E1E28, 2007.

[73] H. Thangarajah, D. C. Yao, E. I. Chang et al., "The molecular basis for impaired hypoxia-induced VEGF expression in diabetic tissues," Proceedings of the National Academy of Sciences of the United States of America, vol. 106, no. 32, pp. 13505-13510, 2009.

[74] M. Pasarica, O. R. Sereda, L. M. Redman et al., "Reduced adipose tissue oxygenation in human obesity evidence for rarefaction, macrophage Chemotaxis, and inflammation without an angiogenic response," Diabetes, vol. 58, no. 3, pp. 718-725, 2009.

[75] S. Nielsen, Z. Guo, C. M. Johnson, D. D. Hensrud, and M. D. Jensen, "Splanchnic lipolysis in human obesity," The Journal of Clinical Investigation, vol. 113, no. 11, pp. 1582-1588, 2004.

[76] Y. S. Lee, J. W. Kim, O. Osborne et al., "Increased adipocyte O2 consumption triggers HIF-1alpha, causing inflammation and insulin resistance in obesity," Cell, vol. 157, no. 6, pp. 1339-1352, 2014.
[77] G. H. Goossens, A. Bizzarri, N. Venteclef et al., "Increased adipose tissue oxygen tension in obese compared with lean men is accompanied by insulin resistance, impaired adipose tissue capillarization, and inflammation," Circulation, vol. 124, no. 1, pp. 67-76, 2011.

[78] S. Cinti, G. Mitchell, G. Barbatelli et al., "Adipocyte death defines macrophage localization and function in adipose tissue of obese mice and humans," Journal of Lipid Research, vol. 46, no. 11, pp. 2347-2355, 2005.

[79] D. Mazzatti, F. L. Lim, A. O'Hara, I. S. Wood, and P. Trayhurn, "A microarray analysis of the hypoxia-induced modulation of gene expression in human adipocytes," Archives of Physiology and Biochemistry, vol. 118, no. 3, pp. 112-120, 2012.

[80] S. Biswas, R. Mukherjee, N. Tapryal, A. K. Singh, and C. K. Mukhopadhyay, "Insulin regulates hypoxia-inducible factor-1 alpha transcription by reactive oxygen species sensitive activation of Sp1 in 3T3-L1 preadipocyte," PloS One, vol. 8, no. 4, article e62128, 2013ARTN e62128.

[81] I. R. Botusan, V. G. Sunkari, O. Savu et al., "Stabilization of HIF-1alpha is critical to improve wound healing in diabetic mice," Proceedings of the National Academy of Sciences of the United States of America, vol. 105, no. 49, pp. 1942619431, 2008.

[82] H. Thangarajah, I. N. Vial, R. H. Grogan et al., "HIF-1alpha dysfunction in diabetes," Cell Cycle (Georgetown, Texas), vol. 9, no. 1, pp. 75-79, 2010.

[83] S. Zhou, S. Lechpammer, J. S. Greenberger, and J. Glowacki, "Hypoxia inhibition of adipocytogenesis in human bone marrow stromal cells requires transforming growth factorbeta/Smad3 signaling," The Journal of Biological Chemistry, vol. 280, no. 24, pp. 22688-22696, 2005.

[84] K. H. Kim, M. J. Song, J. Chung, H. Park, and J. B. Kim, "Hypoxia inhibits adipocyte differentiation in a HDACindependent manner," Biochemical and Biophysical Research Communications, vol. 333, no. 4, pp. 1178-1184, 2005.

[85] C. D. Byrne, "Hypoxia and non-alcoholic fatty liver disease," Clinical Science, vol. 118, no. 6, pp. 397-400, 2010.

[86] S. Fujisaka, I. Usui, M. Ikutani et al., "Adipose tissue hypoxia induces inflammatory M1 polarity of macrophages in an HIF-1alpha-dependent and HIF-1alpha-independent manner in obese mice," Diabetologia, vol. 56, no. 6, pp. 14031412, 2013.

[87] G. L. Semenza, "Hydroxylation of HIF-1: Oxygen sensing at the molecular level," Physiology, vol. 19, no. 4, pp. 176-182, 2004.

[88] S. H. Kim, D. Hwang, H. Park, E. G. Yang, H. S. Chung, and S. Y. Kim, "The action of HIF-3alpha variants on HIF-2alphaHIF-1beta heterodimer formation is directly probed in live cells," Experimental Cell Research, vol. 336, no. 2, pp. 329337, 2015.

[89] Z. Arany, L. E. Huang, R. Eckner et al., "An essential role for p300/CBP in the cellular response to hypoxia," Proceedings of the National Academy of Sciences of the United States of America, vol. 93, no. 23, pp. 12969-12973, 1996.

[90] J. Wan, H. Chai, Z. Yu et al., "HIF-1alpha effects on angiogenic potential in human small cell lung carcinoma," Journal of Experimental \& Clinical Cancer Research : CR, vol. 30, p. 77, 2011.

[91] Q. Ke and M. Costa, "Hypoxia-inducible factor-1 (HIF-1)," Molecular Pharmacology, vol. 70, no. 5, pp. 1469-1480, 2006. 
[92] Y. V. Liu, J. H. Baek, H. Zhang, R. Diez, R. N. Cole, and G. L. Semenza, "RACK1 competes with HSP90 for binding to HIFlalpha and is required for O(2)-independent and HSP90 inhibitor-induced degradation of HIF-1alpha," Molecular Cell, vol. 25, no. 2, pp. 207-217, 2007.

[93] T. Hagen, C. T. Taylor, F. Lam, and S. Moncada, "Redistribution of intracellular oxygen in hypoxia by nitric oxide: effect on HIF1alpha," Science, vol. 302, no. 5652, pp. 1975-1978, 2003.

[94] P. Fraisl, "Crosstalk between oxygen- and nitric oxidedependent signaling pathways in angiogenesis," Experimental Cell Research, vol. 319, no. 9, pp. 1331-1339, 2013.

[95] G. F. Benderro, X. Y. Sun, Y. Z. Kuang, and J. C. LaManna, "Decreased VEGF expression and microvascular density, but increased HIF-1 and 2 alpha accumulation and EPO expression in chronic moderate hyperoxia in the mouse brain," Brain Research, vol. 1471, pp. 46-55, 2012.

[96] A. Leiherer, K. Geiger, A. Muendlein, and H. Drexel, "Hypoxia induces a HIF-1alpha dependent signaling cascade to make a complex metabolic switch in SGBS-adipocytes," Molecular and Cellular Endocrinology, vol. 383, no. 1-2, pp. 21-31, 2014.

[97] C. Jiang, A. Qu, T. Matsubara et al., "Disruption of hypoxiainducible factor 1 in adipocytes improves insulin sensitivity and decreases adiposity in high-fat diet-fed mice," Diabetes, vol. 60, no. 10, pp. 2484-2495, 2011.

[98] X. Zhang, K. S. Lam, H. Ye et al., "Adipose tissue-specific inhibition of hypoxia-inducible factor 1 \{alpha\} induces obesity and glucose intolerance by impeding energy expenditure in mice," The Journal of Biological Chemistry, vol. 285, no. 43, pp. 32869-32877, 2010.

[99] I. Shimizu, T. Aprahamian, R. Kikuchi et al., "Vascular rarefaction mediates whitening of brown fat in obesity," The Journal of Clinical Investigation, vol. 124, no. 5, pp. 2099-2112, 2014.

[100] Y. Xue, N. Petrovic, R. Cao et al., "Hypoxia-independent angiogenesis in adipose tissues during cold acclimation," Cell Metabolism, vol. 9, no. 1, pp. 99-109, 2009.

[101] C. Rammos, M. Totzeck, R. Deenen et al., "Dietary nitrate is a modifier of vascular gene expression in old male mice," Oxidative Medicine and Cellular Longevity, vol. 2015, Article ID 658264, p. 12, 2015.

[102] L. D. Roberts, T. Ashmore, A. O. Kotwica et al., "Inorganic nitrate promotes the browning of white adipose tissue through the nitrate-nitrite-nitric oxide pathway," Diabetes, vol. 64, no. 2, pp. 471-484, 2015.

[103] M. P. Hezel, M. Liu, T. A. Schiffer et al., "Effects of long-term dietary nitrate supplementation in mice," Redox Biology, vol. 5, pp. 234-242, 2015.

[104] R. D. Rudic, E. G. Shesely, N. Maeda, O. Smithies, S. S. Segal, and W. C. Sessa, "Direct evidence for the importance of endothelium-derived nitric oxide in vascular remodeling," The Journal of Clinical Investigation, vol. 101, no. 4, pp. 731-736, 1998.

[105] B. J. Krause, R. Del Rio, E. A. Moya, M. Marquez-Gutierrez, P. Casanello, and R. Iturriaga, "Arginase-endothelial nitric oxide synthase imbalance contributes to endothelial dysfunction during chronic intermittent hypoxia," Journal of Hypertension, vol. 33, no. 3, pp. 515-524, 2015.

[106] J. O. Lundberg, E. Weitzberg, and M. T. Gladwin, “The nitrate-nitrite-nitric oxide pathway in physiology and therapeutics," Nature Reviews Drug Discovery, vol. 7, no. 2, pp. 156-167, 2008.
[107] N. S. Bryan and M. B. Grisham, "Methods to detect nitric oxide and its metabolites in biological samples," Free Radical Biology \& Medicine, vol. 43, no. 5, pp. 645-657, 2007.

[108] B. McNally, J. L. Griffin, and L. D. Roberts, "Dietary inorganic nitrate: From villain to hero in metabolic disease?" Molecular Nutrition \& Food Research, vol. 60, no. 1, pp. 67-78, 2016.

[109] S. Dauncey, "Can dietary nitrate supplements improve tolerance to hypoxia?" Journal of the Intensive Care Society, vol. 13, no. 3, pp. 198-204, 2012.

[110] A. Ghasemi and S. Zahediasl, "Is nitric oxide a hormone?" Iranian Biomedical Journal, vol. 15, no. 3, pp. 59-65, 2011.

[111] C. P. Prieto, B. J. Krause, C. Quezada, R. San Martin, L. Sobrevia, and P. Casanello, "Hypoxia-reduced nitric oxide synthase activity is partially explained by higher arginase- 2 activity and cellular redistribution in human umbilical vein endothelium," Placenta, vol. 32, no. 12, pp. 932-940, 2011.

[112] X. Gao, X. Xu, S. Belmadani et al., "TNF-alpha contributes to endothelial dysfunction by upregulating arginase in ischemia/reperfusion injury," Arteriosclerosis, Thrombosis, and Vascular Biology, vol. 27, no. 6, pp. 1269-1275, 2007.

[113] M. Singh, G. Padhy, P. Vats, K. Bhargava, and N. K. Sethy, "Hypobaric hypoxia induced arginase expression limits nitric oxide. availability and signaling in rodent heart," Biochimica et Biophysica Acta-General Subjects, vol. 1840, no. 6, pp. 1817-1824, 2014.

[114] J. Pernow and C. Jung, "Arginase as a potential target in the treatment of cardiovascular disease: reversal of arginine steal?" Cardiovascular Research, vol. 98, no. 3, pp. 334-343, 2013.

[115] H. Wang, A. X. Wang, K. Aylor, and E. J. Barrett, "Nitric oxide directly promotes vascular endothelial insulin transport," Diabetes, vol. 62, no. 12, pp. 4030-4042, 2013.

[116] M. A. Potenza, F. L. Marasciulo, D. M. Chieppa et al., "Insulin resistance in spontaneously hypertensive rats is associated with endothelial dysfunction characterized by imbalance between NO and ET-1 production," American Journal of Physiology-Heart and Circulatory Physiology, vol. 289, no. 2, pp. H813-HH22, 2005.

[117] J. A. Kim, M. Montagnani, K. K. Koh, and M. J. Quon, "Reciprocal relationships between insulin resistance and endothelial dysfunction - molecular and pathophysiological mechanisms," Circulation, vol. 113, no. 15, pp. 1888-1904, 2006.

[118] B. Spiegelhalder, G. Eisenbrand, and R. Preussmann, "Influence of dietary nitrate on nitrite content of human saliva: possible relevance to in vivo formation of N-nitroso compounds," Food and Cosmetics Toxicology, vol. 14, no. 6, pp. 545-548, 1976.

[119] P. F. Swann, "Carcinogenic risk from nitrite, nitrate and Nnitrosamines in food," Proceedings of the Royal Society of Medicine, vol. 70, no. 2, pp. 113-115, 1977.

[120] A. S. Pannala, A. R. Mani, J. P. Spencer et al., "The effect of dietary nitrate on salivary, plasma, and urinary nitrate metabolism in humans," Free Radical Biology \& Medicine, vol. 34, no. 5, pp. 576-584, 2003.

[121] Y. Tang, H. Jiang, and N. S. Bryan, "Nitrite and nitrate: cardiovascular risk-benefit and metabolic effect," Current Opinion in Lipidology, vol. 22, no. 1, pp. 11-15, 2011.

[122] T. Nyström, H. Ortsäter, Z. Huang et al., "Inorganic nitrite stimulates pancreatic islet blood flow and insulin secretion," Free Radical Biology \& Medicine, vol. 53, no. 5, pp. 10171023, 2012. 
[123] F. Kim, K. A. Tysseling, J. Rice et al., "Free fatty acid impairment of nitric oxide production in endothelial cells is mediated by IKK $\beta$," Arteriosclerosis, Thrombosis, and Vascular Biology, vol. 25, no. 5, pp. 989-994, 2005.

[124] L. Jia, C. R. Vianna, M. Fukuda et al., "Hepatocyte Toll-like receptor 4 regulates obesity-induced inflammation and insulin resistance," Nature Communications, vol. 5, p. 3878, 2014.

[125] T. Yang, M. Peleli, C. Zollbrecht et al., "Inorganic nitrite attenuates NADPH oxidase-derived superoxide generation in activated macrophages via a nitric oxide-dependent mechanism," Free Radical Biology \& Medicine, vol. 83, pp. 159166, 2015.

[126] M. Carlstrom, A. E. Persson, E. Larsson et al., "Dietary nitrate attenuates oxidative stress, prevents cardiac and renal injuries, and reduces blood pressure in salt-induced hypertension," Cardiovascular Research, vol. 89, no. 3, pp. 574-585, 2011, cvq366 [pii].

[127] S. Jeddi, S. Khalifi, M. Ghanbari, F. Bageripour, and A. Ghasemi, "Effects of nitrate intake on myocardial ischemiareperfusion injury in diabetic rats," Arquivos Brasileiros de Cardiologia, vol. 107, no. 4, pp. 339-347, 2016.

[128] E. H. Chiu, C. S. Liu, T. Y. Tan, and K. C. Chang, "Venturi mask adjuvant oxygen therapy in severe acute ischemic stroke," Archives of Neurology, vol. 63, no. 5, pp. 741-744, 2006.

[129] T. Toyama, R. Seki, S. Kasama et al., "Effectiveness of nocturnal home oxygen therapy to improve exercise capacity, cardiac function and cardiac sympathetic nerve activity in patients with chronic heart failure and central sleep apnea," Circulation Journal : Official Journal of the Japanese Circulation Society, vol. 73, no. 2, pp. 299-304, 2009.

[130] M. H. Bennett, J. Feldmeier, R. Smee, and C. Milross, "Hyperbaric oxygenation for tumour sensitisation to radiotherapy," The Cochrane Database of Systematic Reviews, vol. 4, article CD005007, 2012.

[131] Y. Feldman-Idov, Y. Melamed, S. Linn, and L. Ore, "Prognostic factors predicting ischemic wound healing following hyperbaric oxygenation therapy," Wound Repair and Regeneration : Official Publication of the Wound Healing Society [and] the European Tissue Repair Society, vol. 21, no. 3, pp. 418-427, 2013.

[132] D. Wilkinson, I. M. Chapman, and L. K. Heilbronn, "Hyperbaric oxygen therapy improves peripheral insulin sensitivity in humans," Diabetic Medicine: A Journal of the British Diabetic Association, vol. 29, no. 8, pp. 986-989, 2012.

[133] H. Kato, J. Araki, K. Doi et al., "Normobaric hyperoxygenation enhances initial survival, regeneration, and final retention in fat grafting," Plastic and Reconstructive Surgery, vol. 134, no. 5, pp. 951-959, 2014.

[134] T. Matsunaga, S. Li, T. Adachi et al., "Hyperoxia reverses glucotoxicity-induced inhibition of insulin secretion in rat INS-1 beta cells," Bioscience, Biotechnology, and Biochemistry, vol. 78, no. 5, pp. 843-850, 2014.

[135] N. Fujita, F. Nagatomo, S. Murakami, H. Kondo, A. Ishihara, and H. Fujino, "Effects of hyperbaric oxygen on metabolic capacity of the skeletal muscle in type 2 diabetic rats with obesity," The Scientific World Journal, vol. 2012, Article ID 637978, p. 9, 2012.

[136] Z. Zhang, X. Bai, K. Du et al., "Activation of cholinergic antiinflammatory pathway contributes to the protective effects of $100 \%$ oxygen inhalation on zymosan-induced generalized inflammation in mice," The Journal of Surgical Research, vol. 174, no. 2, pp. e75-e83, 2012.

[137] H. D. Wilson, J. R. Wilson, and P. N. Fuchs, "Hyperbaric oxygen treatment decreases inflammation and mechanical hypersensitivity in an animal model of inflammatory pain," Brain Research, vol. 1098, no. 1, pp. 126-128, 2006.

[138] S. Milstien and Z. Katusic, "Oxidation of tetrahydrobiopterin by peroxynitrite: implications for vascular endothelial function," Biochemical and Biophysical Research Communications, vol. 263, no. 3, pp. 681-684, 1999.

[139] S. R. Thom, "Oxidative stress is fundamental to hyperbaric oxygen therapy," Journal of Applied Physiology, vol. 106, no. 3, pp. 988-995, 2009.

[140] A. Marti, M. A. Martinez-Gonzalez, and J. A. Martinez, "Interaction between genes and lifestyle factors on obesity," Proceedings of the Nutrition Society, vol. 67, no. 1, pp. 1-8, 2008.

[141] A. Misra and L. Khurana, "Obesity and the metabolic syndrome in developing countries," The Journal of Clinical Endocrinology and Metabolism, vol. 93, no. 11, Supplement 1, pp. S9-30, 2008.

[142] P. Gonzalez-Muniesa, A. Lopez-Pascual, J. de Andres et al., "Impact of intermittent hypoxia and exercise on blood pressure and metabolic features from obese subjects suffering sleep apnea-hypopnea syndrome," Journal of Physiology and Biochemistry, vol. 71, no. 3, pp. 589-599, 2015.

[143] F. J. Lippl, S. Neubauer, S. Schipfer et al., "Hypobaric hypoxia causes body weight reduction in obese subjects," Obesity, vol. 18, no. 4, pp. 675-681, 2010.

[144] A. Lopez-Pascual, M. Bes-Rastrollo, C. Sayon-Orea et al., "Living at a geographically higher elevation is associated with lower risk of metabolic syndrome: prospective analysis of the SUN cohort," Frontiers in Physiology, vol. 7, p. 658, 2017, ARTN 658.

[145] B. Ostadal and F. Kolar, "Cardiac adaptation to chronic highaltitude hypoxia: Beneficial and adverse effects," Respiratory Physiology \& Neurobiology, vol. 158, no. 2-3, pp. 224-236, 2007.

[146] P. Quintero, F. I. Milagro, J. Campion, and J. A. Martinez, "Impact of oxygen availability on body weight management," Medical Hypotheses, vol. 74, no. 5, pp. 901-907, 2010.

[147] C. T. Taylor, B. D. Kent, S. J. Crinion, W. T. McNicholas, and S. Ryan, "Human adipocytes are highly sensitive to intermittent hypoxia induced NF-kappaB activity and subsequent inflammatory gene expression," Biochemical and Biophysical Research Communications, vol. 447, no. 4, pp. 660-665, 2014.

[148] M. Londahl, P. Katzman, A. Nilsson, and C. Hammarlund, "Hyperbaric oxygen therapy facilitates healing of chronic foot ulcers in patients with diabetes," Diabetes Care, vol. 33, no. 5, pp. 998-1003, 2010.

[149] P. Tahep ld, G. Valen, J. Starkopf, C. Kairane, M. Zilmer, and J. Vaage, "Pretreating rats with hyperoxia attenuates ischemia-reperfusion injury of the heart," Life Sciences, vol. 68, no. 14, pp. 1629-1640, 2001.

[150] H. Farquhar, M. Weatherall, M. Wijesinghe et al., "Systematic review of studies of the effect of hyperoxia on coronary blood flow," American Heart Journal, vol. 158, no. 3, pp. 371-377, 2009.

[151] E. A. Resseguie, R. J. Staversky, P. S. Brookes, and M. A. O'Reilly, "Hyperoxia activates ATM independent from 
mitochondrial ROS and dysfunction," Redox Biology, vol. 5, pp. 176-185, 2015.

[152] M.Entezari, M. Javdan, D. J. Antoine et al., "Inhibition of extracellular HMGB1 attenuates hyperoxia-induced inflammatory acute lung injury," Redox Biology, vol. 2, pp. 314-322, 2014.

[153] Y. Kanda, T. Hinata, S. W. Kang, and Y. Watanabe, "Reactive oxygen species mediate adipocyte differentiation in mesenchymal stem cells," Life Sciences, vol. 89, no. 7-8, pp. 250258, 2011.

[154] Y. Xiong, M. Lei, S. Fu, and Y. Fu, "Effect of diabetic duration on serum concentrations of endogenous inhibitor of nitric oxide synthase in patients and rats with diabetes," Life Sciences, vol. 77, no. 2, pp. 149-159, 2005.

[155] M. Carlstrom, F. J. Larsen, T. Nystrom et al., "Dietary inorganic nitrate reverses features of metabolic syndrome in endothelial nitric oxide synthase-deficient mice," Proceedings of the National Academy of Sciences of the United States of America, vol. 107, no. 41, pp. 17716-17720, 2010.

[156] G. H. Goossens and E. E. Blaak, "Adipose tissue dysfunction and impaired metabolic health in human obesity: A matter of oxygen?” Frontiers in Endocrinology, vol. 6, p. 55, 2015.

[157] L. Landini, M. J. Honka, E. Ferrannini, and P. Nuutila, “Adipose tissue oxygenation in obesity: a matter of cardiovascular risk?" Current Pharmaceutical Design, vol. 22, no. 1, pp. 6876, 2015. 


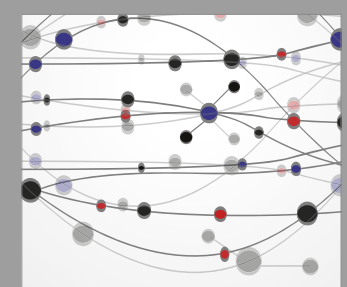

The Scientific World Journal
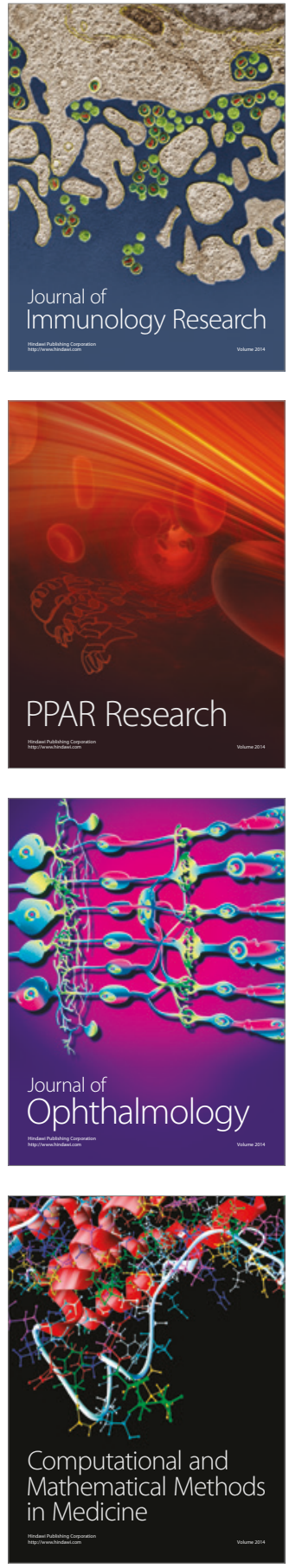

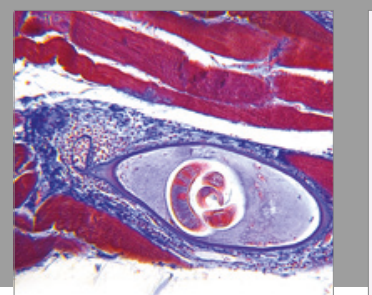

Gastroenterology Research and Practice
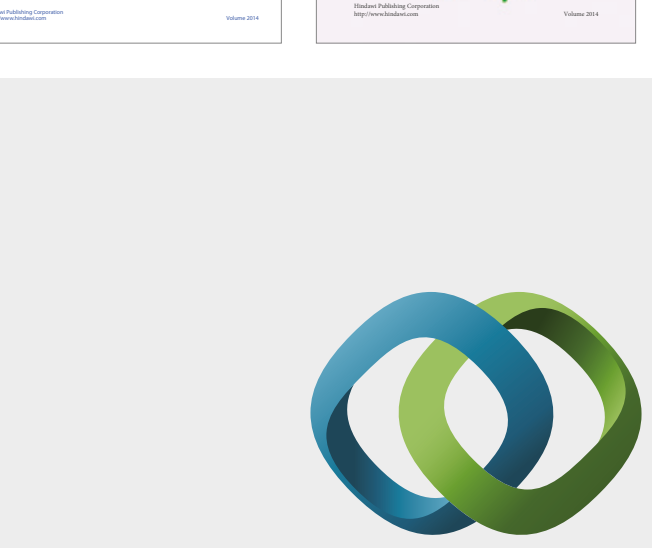

\section{Hindawi}

Submit your manuscripts at

https://www.hindawi.com
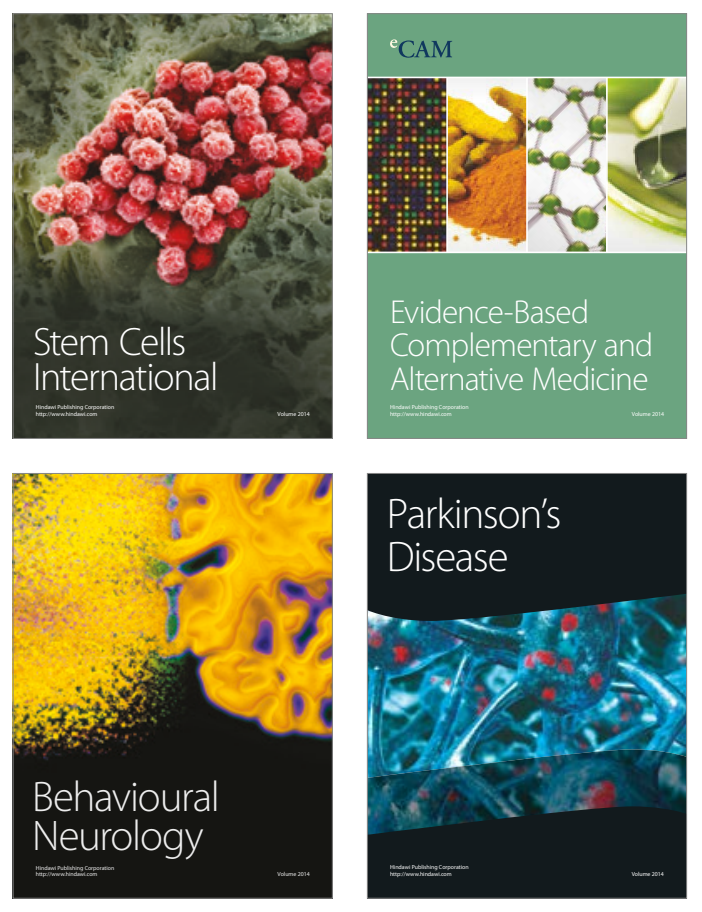
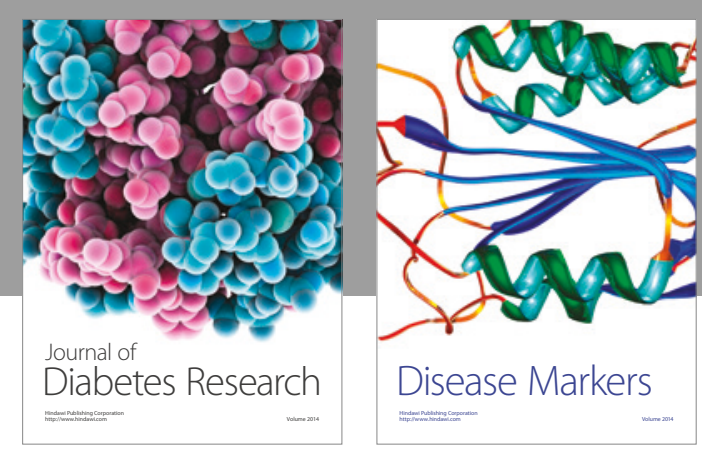

Disease Markers
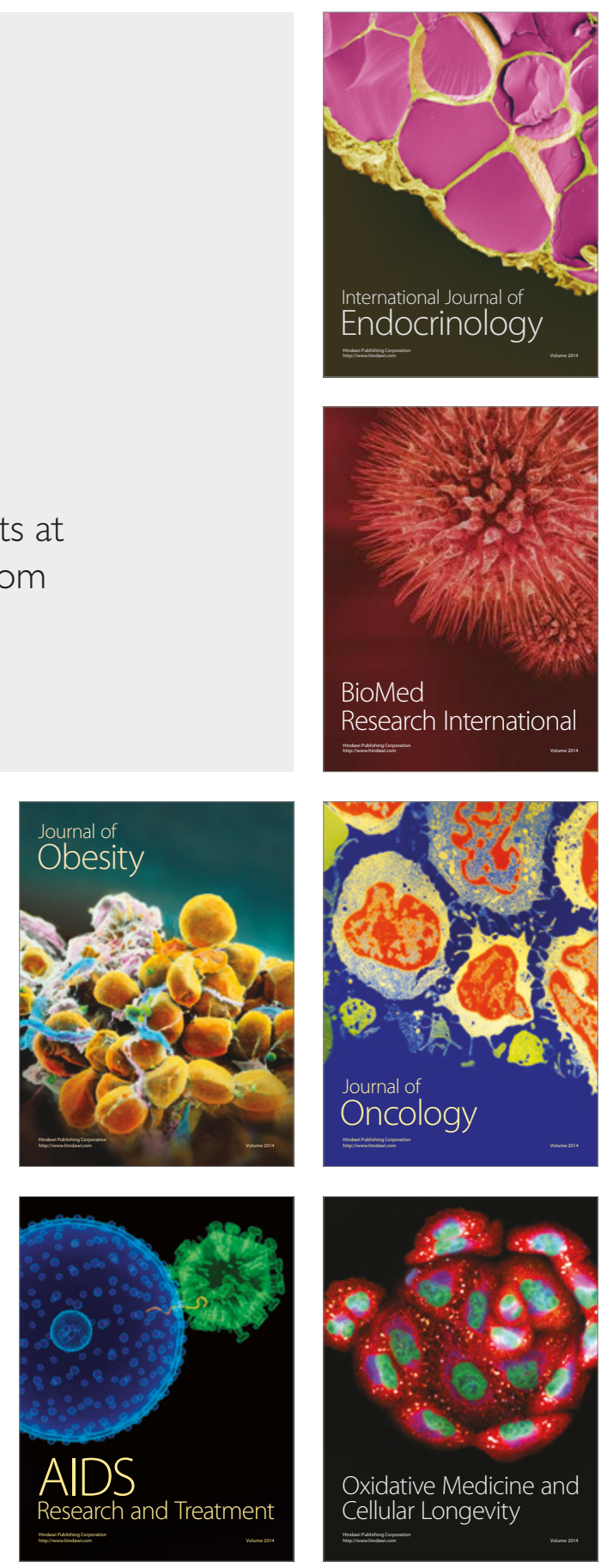